\title{
ECC
}

\section{Simultaneous determination of dopamine and uric acid using a glassy carbon paste electrode modified with copper- para red complex}

\author{
Homa Shafiekhani ${ }^{\mathrm{a},{ }^{*},}$, Fatemeh Mostaghnia, Naimeh Rad ${ }^{\mathrm{b}}$ \\ ${ }^{a}$ Chemistry Department, Payame Noor University, P.O. BOX 19395-4697 Tehran, Iran \\ 'Islamic Azad University, Lamerd Branch, P.O. BOX 74341-553881, Iran
}

Received: 1 August 2018, Accepted: 12 May 2019, Published: 1 September 2019

\begin{abstract}
A simple approach based on cyclic voltammetry (CV) was developed for the simultaneous determination of dopamine (DA) and uric acid (UA) in the presence of ascorbic acid (AA) using a modified glassy carbon paste electrode (GCPE). In the present study, analytical parameters were optimized and electrochemical performance of the modified electrode was investigated. The calibration curves were obtained over the range of 15.97-157.98 $\mu \mathrm{mol} \mathrm{L}^{-1}$ dopamine and 15.97-195.35 $\mu \mathrm{mol} \mathrm{L}^{-1}$ uric acid. Detection limits of $4.8 \mu \mathrm{mol} \mathrm{L} \mathrm{L}^{-1}$ for dopamine and $3 \mu \mathrm{mol} \mathrm{L} \mathrm{L}^{-1}$ for uric acid were obtained at $\mathrm{pH}$ 7.0. The modified electrode was used for the detection of dopamine and uric acid in the real samples such as human serum and urine samples.
\end{abstract}

Keywords: Glassy carbon paste electrode; dopamine; uric acid; electrochemical sensor.

\section{Introduction}

Improvement of electrochemical systems for the detection of ascorbic acid (AA), dopamine (DA) and uric acid (UA) in human urine samples and blood serum have gotten extensive consideration in the literature [1-4]. AA is an exceptionally basic electroactive biological molecule, which is extremely outstanding to prevent scurvy, and is crucial to keep up great immune response and help wound healing [5]. Dopamine, which is the most critical among the class of catecholamine, plays a vital role in the functioning of the central nervous, renal, hormonal and cardiovascular systems [6,7]. Any change in concentrations of dopamine ends up to neurological disorders. Parkinson's disease and schizophrenia are some of the examples of problems associated with abnormal dopamine levels [8]. Uric acid is the primary product of purine metabolism [9], abnormal levels of UA are symptoms of a few illness like gout, hyperuricaemia [10] enhanced urate level moreover prompts pneumonia and leukemia [11]. A major problem in DA determination is the resolution between DA and coexisting species such as ascorbic acid (AA) and uric acid (UA). As reported, the concentration of AA is generally much higher than that of DA (100 to 1000 times) [12]. At traditional solid electrodes, AA and UA are oxidized at 
potentials close to that of DA, resulting in an overlapping voltammetric response [13-15]. Different strategies and chemically modified electrodes (CMEs) have been applied to analyze these molecules because of their interesting oxidation mechanism and role in biological system [16-21].

Most CMEs usually show high sensitivity and high selectivity because of the judicious choice of modifier and control of the electrode potential [29,30]. Currently, chemically modified electrodes (CMEs) play an essential role as the sensitive and selective analytical methods for the environmental, clinical and biotechnical analyses and have been the subject of many investigations [22, 23, 24-28].

Therefore, for electroanalytical applications they are very well suited. Much of this effort has involved carbon-based materials, such as glassy carbon and carbon paste, which have already had much success in recent decades. However, all the modified electrodes have their advantages and limitations [31]. In the present work, the electrochemical behavior of a glassy carbon paste electrode modified with Para $\mathrm{Red} / \mathrm{Cu}^{2+}$ complex (PR/ $\mathrm{Cu}^{2+} / \mathrm{GCPE}$ ) was investigated as a new sensor for detection of DA and UA in the presence of high concentration of AA. The mechanism of electrochemical oxidation of DA, AA, UA using para red modified electrode was thoroughly investigated by square wave voltammetry. The $\mathrm{PR} / \mathrm{Cu}^{2+} / \mathrm{GCPE}$ showed excellent catalytic activity towards electrochemical oxidation of DA and UA in comparison to that of the bare graphite electrode. The proposed method had satisfactory results for the simultaneous detection of DA and UA in DA and UA injection, human serum and urine samples. Under optimized conditions, a good linearity was obtained between the current response and DA, UA concentrations.

\section{Experimental \\ Material and instruments}

Electrochemical systems were carried out using a computerized potentiostat/ galvanostat (Auto lab PGSTAT30, Utrecht, Netherlands) and software of NOVA1.5. A Pentium IV computer controlled all settings and data processing of the system. All the electrochemical studies were performed at $25 \pm 1^{\circ} \mathrm{C}$. A three electrode cell assemblage consisting of saturated calomel electrode (SCE) as reference electrode, a platinum wire counter electrode and a glassy carbon electrode as the working electrode were reported with respect to this reference electrode. The $\mathrm{pH}$ measurements were done with a Metrohm model $827 \mathrm{pH} / \mathrm{mV}$ meters. Dopamine, AA and UA were purchased from Merck and used as received. All other reagents were of reagent grade and used without further purification.

All solutions were prepared with doubly distilled water. The Phosphate buffer solutions (PBS) $0.1 \mathrm{molL}^{-1}$ used as supporting electrolyte were prepared from $0.1 \mathrm{~mol} \mathrm{~L}^{-1} \mathrm{Na}_{2} \mathrm{HPO}_{4}-\mathrm{NaH}_{2} \mathrm{PO}_{4}$, and the $\mathrm{pH}$ was adjusted with $1.0 \mathrm{~mol}$ $\mathrm{L}^{-1} \mathrm{NaOH}$. A $0.010 \mathrm{~mol} \mathrm{~L}^{-1} \mathrm{DA}$ and $0.010 \mathrm{~mol} \mathrm{~L}^{-1} \mathrm{AA}$ solutions were daily prepared by dissolving adequate amounts of dopamine hydrochloride and ascorbic acid in water. Uric acid solution $\left(0.010 \mathrm{~mol} \mathrm{~L}^{-1}\right)$ was prepared by dissolving the solid in a small volume of $0.1 \mathrm{~mol} \mathrm{~L}^{-1} \mathrm{NaOH}$ solution and diluted to desired concentration. Other dilute solutions were prepared by suitable dilution of these solutions in PBS, pH 7.0. All tested solutions were de-aerated by passing high purity nitrogen before the electrochemical experiments and a continuous flow of nitrogen was kept over the sample solution during the experiments. 


\section{Synthesis of Para Red}

The colorant, 1-(p-nitrophenylazo)-2naphthol, (Para Red, PR) was synthesized in two steps [29]. In the first step: A solution of $1 \mathrm{~mol} \mathrm{~L}^{-1}$ sulfuric acid $(10 \mathrm{~mL})$ was prepared, to this was added 4-nitroaniline (1g, 7 mmol) and the mixture was gently heated. The mixture was cooled to about $10{ }^{\circ} \mathrm{C}$ in an ice bath while stirring. To the suspension of $\mathrm{p}$ nitroaniline, sulfate was added a solution of sodium nitrite solution in water $\left(1 \mathrm{~mol} \mathrm{~L} \mathrm{~L}^{-1}, 10 \mathrm{~mL}\right)$. Then, solution of $1 \mathrm{~g}$ (7 mmol) of 2-naphthol in $10 \mathrm{~mL}$ of $2.5 \mathrm{~mol} \mathrm{~L} \mathrm{~L}^{-1}$ sodium hydroxide was added into the flask in an ice bath, with strongly stirring for 30 min. The mixture was acidified with 1molL ${ }^{-1}$ sulfuric acid. The precipitate formed was filtered and washed with water. The crude product was purified by recrystallization. The red product (Figure 1) was characterized by FTIR spectroscopy. Yield 75\%; purity > 98\%; mp: $245-246 \circ \mathrm{C}$. The complex of Para Red- $\mathrm{Cu} 2+$ is shown in Figure 2.

IR $\left(\mathrm{KBr}, \mathrm{cm}^{-1}\right): 3423(\mathrm{~m}, \mathrm{OH})$, 1593 (s, C=C), 1501 (s, asym $\mathrm{NO}_{2}$ ), 1338 (s, sym NO $\mathrm{N}_{2}$ ), 860 (s, C-H), 836 (s, C-H). Accurate Mass: $\mathrm{C}_{16} \mathrm{H}_{12} \mathrm{~N}_{3} \mathrm{O}_{3}$ requires 292.0719 found 292.0727.

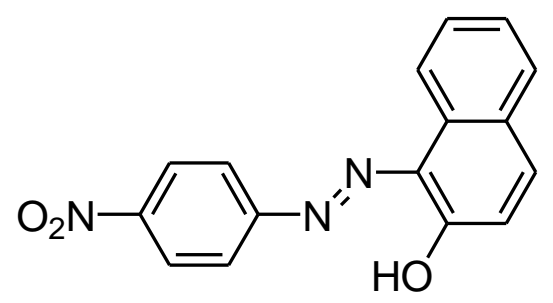

Figure 1. Molecular structure of Para Red

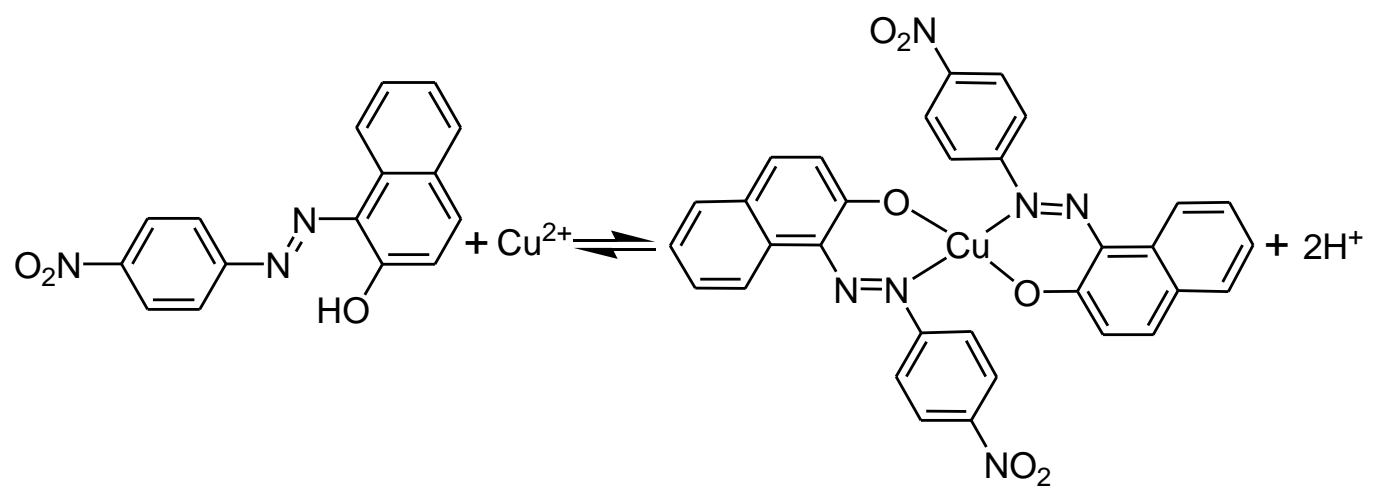

Figure 2. The molecular structure of Para Red- $\mathrm{Cu}^{2+}$ complex

\section{Preparation of Para Red-Cu $\mathbf{C u}^{2+}$ modified glassy carbon electrode}

Before modification, the bare glassy carbon electrode (GCE) was polished with $0.05 \mu \mathrm{m} \mathrm{Al}_{2} \mathrm{O}_{3}$ slurry on the polishing cloth and then rinsed with distilled water. After being cleaned, for electrochemical activation of the electrode, it was immersed in $0.5 \mathrm{~mol}$ $\mathrm{L}^{-1} \mathrm{H}_{2} \mathrm{SO}_{4}$ solution and was activated by cyclic sweeping from -1.0 to $1.0 \mathrm{~V}$ at scan rate100 $\mathrm{mVs}^{-1}$, until a stable voltammogram was obtained. Subsequently, the activated electrode was rinsed with doubly distilled water and dried in the air. The modified electrode was fabricated as follows: Carbon paste was prepared by mixing graphite powder and mineral oil at the ratio 70/30 (w/w). The paste was carefully hand mixed in a mortar and then $80 \mu \mathrm{L}$ solution of $\mathrm{Cu}^{2+}-\mathrm{PR}$ in 
acetonitrile was added. This paste sets in the glassy carbon electrode. After the modification, the modified electrode $(\mathrm{Cu} / \mathrm{PR} / \mathrm{GCPE})$ was washed with doubly-distilled water and scan cycled in $\mathrm{pH} 7.0$ (PBS) between -1.0 and 1.0 for 20 times to increase its reproducibility. When the modified electrode was not in use, it was stored in a desiccator at room temperature.

\section{Results and discussion \\ Electrochemical characteristics of Cu/PR/GC}

The electrocatalytic activity of $\mathrm{Cu} / \mathrm{PR} / \mathrm{GCPE}$ electrode was evaluated for the simultaneous determination of dopamine and uric acid using cyclic voltammetry method. Figure 3 shows cyclic voltammetric responses of the modified electrode in $0.1 \mathrm{~mol} \mathrm{~L}^{-1}$ phosphate buffer at the potential range of -1 to $1 \mathrm{~V}$ at $100 \mathrm{mV} \mathrm{s}{ }^{1}$ sweep rate.

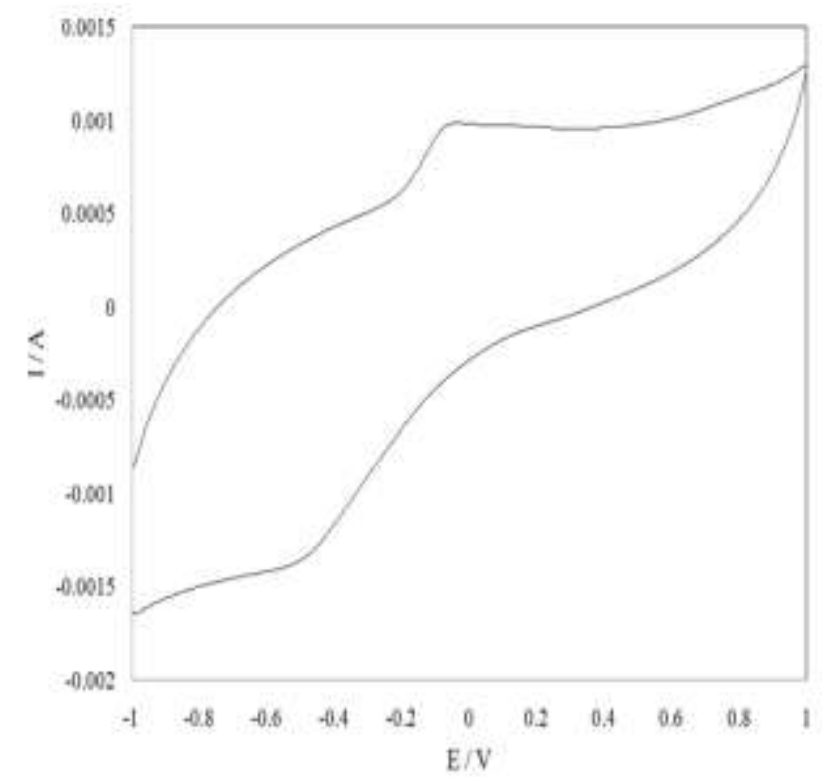

Figure 3. Cyclic voltammograms of modified electrode in $0.1 \mathrm{~mol} \mathrm{~L}^{-1}$ phosphate buffer of $(\mathrm{pH}=7.0)$ at scan rate $100 \mathrm{mV} \mathrm{s}^{-1}$

A pair of redox peak at $(\mathrm{Cu} / \mathrm{PR} / \mathrm{GCPE})$ electrodes was gotten with anodic peak potential situated at $89 \mathrm{mV}$ and cathodic peak potential at $510 \mathrm{mV}$ with a formal potential of -299 $\mathrm{mV}$. The separation of redox peaks $\left(\Delta E_{p}\right)$ was found to be $421 \mathrm{mV}$.

\section{Effect of scan rate}

The effect of the scan rate on the anodic and cathodic peak current of modified electrode $(\mathrm{Cu} / \mathrm{PR} / \mathrm{GCPE})$ was studied by cyclic voltammetric technique (Figure 4). The results showed that the peak current increased with increasing scan rate $\left(10-1250 \mathrm{mVs}^{-1}\right)$. The graph of redox peak current $\left(\mathrm{I}_{\mathrm{p}}\right)$ vs. scan rate (v) was plotted and a good linearity between scan rates and peak current was obtained as shown in Figure 5. The redox peak currents were proportional to $\left(v^{1 / 2}\right)$. The correlation coefficient $\left(r^{2}\right)$ of $\mathrm{I}_{\mathrm{pa}}$ and $\mathrm{I}_{\mathrm{pc}}$ were 0.9946 and 0.9970 , respectively, which indicates that the electrode reaction was a diffusion controlled process. 


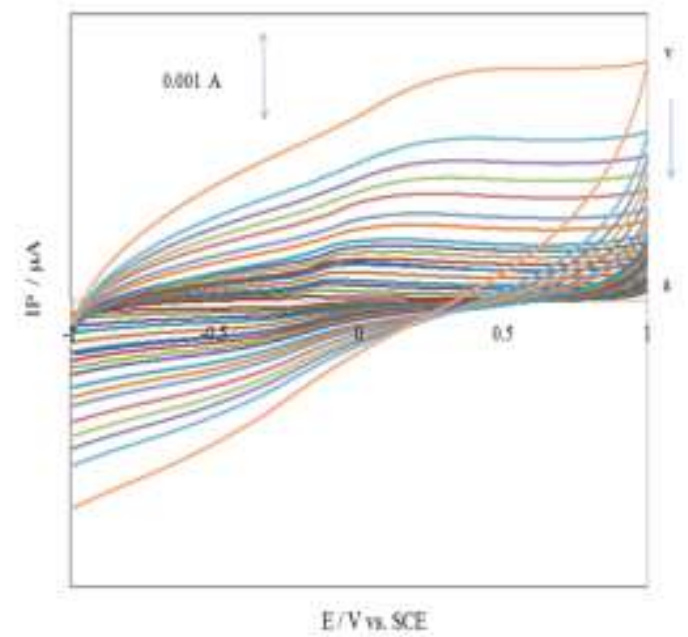

Figure 4. Cyclic voltammograms of $\mathrm{Cu} / \mathrm{PR} / \mathrm{GCPE}$ electrodes in $0.1 \mathrm{~mol} \mathrm{~L}-1 \mathrm{PBS}$ solution of $(\mathrm{pH}=7.0)$ at various scan rates $\left(\begin{array}{lllllll}10 & \mathrm{mV} & \mathrm{s}-1 & \mathrm{to} & 1250 & \mathrm{mV} & \mathrm{s}-1\end{array}\right)$

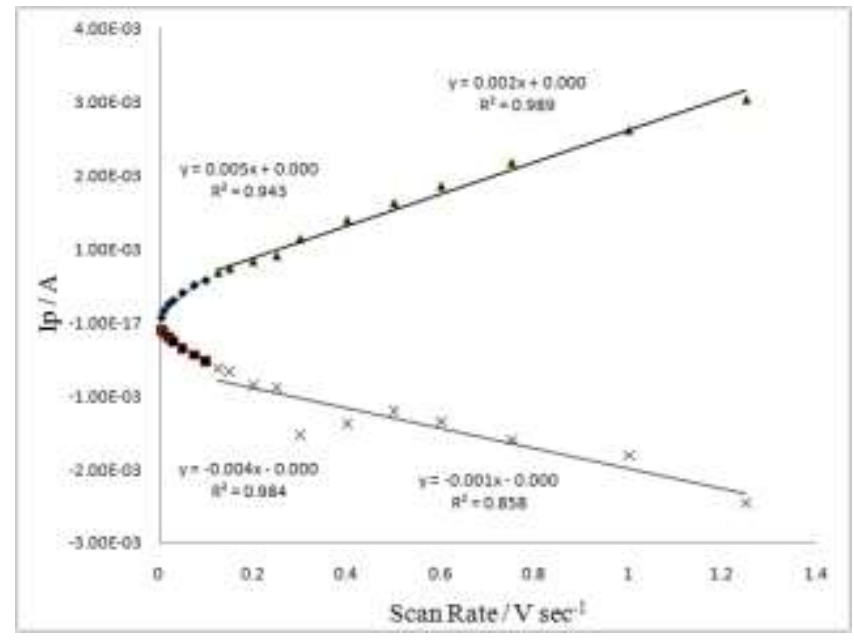

Figure 5. The graph shows the linear relationship between the peak current and the scan rate

Furthermore, a linear correlation was obtained between peak potentials $\left(E_{p}\right)$ and logarithm of the scan rates for scan rates below $200 \mathrm{mV} \mathrm{s}^{-1}$. Two linear regression equations of $\mathrm{E}_{\mathrm{pa}}$ and $\mathrm{E}_{\mathrm{pc}}$ on $\log v$ were as follows:

$$
E_{p a}(\vartheta)=0.0867+0.0307(\gamma=
$$

\subsection{3)}

$$
\begin{gathered}
E_{p c}(\vartheta)=-4.35 \log \vartheta-2.9(\gamma \\
=0.964)
\end{gathered}
$$

According to the theory given by Laviron, constant electron transfers rate $\left(\mathrm{k}_{\mathrm{s}}\right)$ can be calculated from the variation of $E_{p a}$ and $E_{p c}$ with the logarithm of the scan rate [32].
The slope of the linear equation is equal to $-2.3 \mathrm{RT} / \alpha_{\mathrm{c}} \mathrm{nF}$ and $2.3 \mathrm{RT} / \alpha_{\mathrm{a}} \mathrm{nF}$ corresponding to the cathodic and anodic peak, respectively which can be used to evaluate the kinetic parameters, $\alpha_{c}$ and $\alpha_{a}$. In this equation, $R, T$ and $F$ are referred to gas constant, temperature and Faraday constant, respectively. Here, the anodic transfer coefficient $\left(\alpha_{\mathrm{a}}\right)$ is 0.45 and the number of electron ( $\mathrm{n}$ ) involved in the reaction is $0.61 \approx 1$. Meanwhile, the electron transfer rate constant $\left(\mathrm{k}_{\mathrm{s}}\right)$ is calculated $0.39 \mathrm{~s}^{-1}$ using the following Laviron's equation [33]: 


$$
\begin{aligned}
\log \mathrm{K}_{\mathrm{s}}=\alpha \log & (1-\alpha) \\
& +(1-\alpha) \log \left(\frac{\mathrm{RT}}{\mathrm{nF} \vartheta}\right) \\
& -\alpha(1-\alpha) \frac{\mathrm{nF} \Delta \mathrm{E}_{\mathrm{F}}}{2.3 \mathrm{RT}}
\end{aligned}
$$

According to Laviron method, the peak current is related to the surface concentration of electroactive species, $\Gamma$, by the equation: $\mathrm{Q}=\mathrm{nFA} \Gamma$. Where $\mathrm{n}$ represents the number of electrons involved in the reaction, $A$ is the surface area of the electrode and $\Gamma$ is the surface coverage concentration (mol $\mathrm{cm}^{-2}$ ). From the slope of anodic peak currents versus scan rate the calculated surface concentration of copper para red complex is $2.26 \times 10^{-9} \mathrm{~mol} \mathrm{~cm}^{-2}$ for $\mathrm{n}$ $=1$.

\section{Experimental parameters}

In order to study the effect of $\mathrm{pH}$ on peak currents and potentials of AA, DA and UA, they were studied by cyclic voltammetry by varying of $\mathrm{pH}\left(2.0^{-}\right.$ 8.0). Figure 6 shows the dependence of their peak currents on the $\mathrm{pH}$ level of the solution. Since different compounds have different $\mathrm{pK}_{\mathrm{a}}$, varying in the $\mathrm{pH}$ has different effects on the peak currents. It can be realized that the anodic peak currents of DA and UA reach a maximum at $\mathrm{pH} 7.0$, and then potential decreases slowly with increasing of $\mathrm{pH}$ value. With increasing $\mathrm{pH}$, their oxidation peak potentials shifted negatively and the potential of DA and UA were 200 and $350 \mathrm{mV}$ respectively. As can be seen in Figure 6, at $\mathrm{pH} 7.0$, DA and UA had maximum oxidation currents, even though at $\mathrm{pH}$ 7.0 anodic peak current of AA was not seen. Thus, for simultaneous determination of these compounds, a $\mathrm{pH}$ value of 7.0 (PBS, $0.1 \mathrm{~mol} \mathrm{~L}^{-1}$ ) was selected for further study. The CV parameters including pulse amplitude, pulse time, and voltage step time were changing when the concentration of DA and UA on the cell were $20 \mu \mathrm{mol} \mathrm{L}{ }^{-1}$.

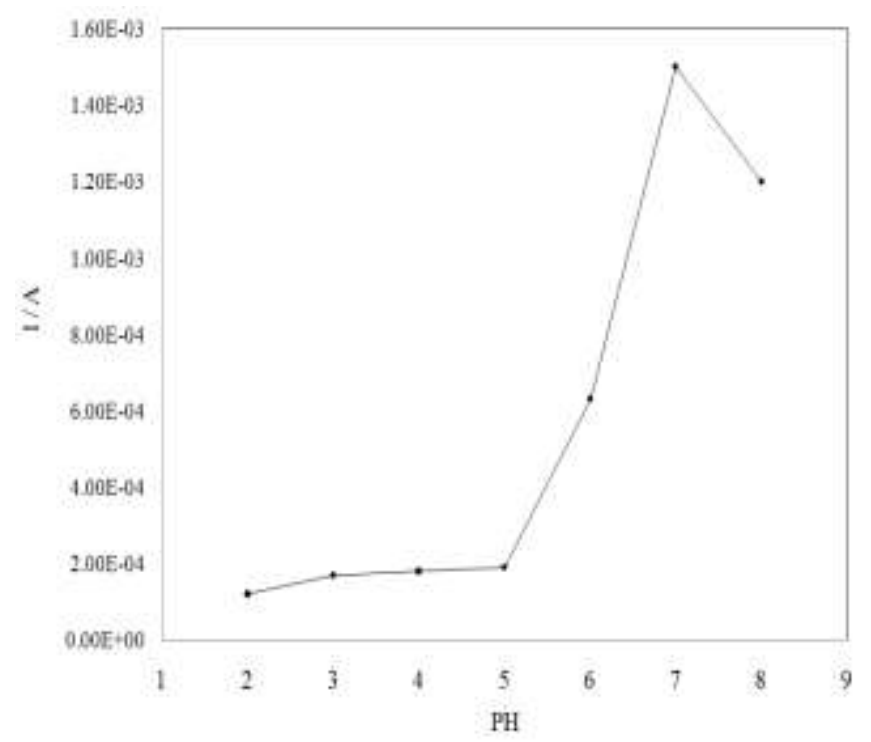

Figure 6. Cyclic voltammograms of $\mathrm{Cu} / \mathrm{PR} / \mathrm{GCPE}$ electrodes in $\mathrm{pH}$ (2.0-8.0) for simultaneous determination of $20.0 \mu \mathrm{mol} \mathrm{L}-1$ UA and DA at scan rate of $100 \mathrm{mV} \mathrm{s}^{-1}$

\section{Simultaneous determination of AA,} $D A$, and $U A$

The main aim of the present investigation is to determine the DA and $\mathrm{UA}$ in the presence of $\mathrm{AA}$ simultaneously. The simultaneous determination of DA, AA and UA mixture (Figure 7, dash line), at the 
bare electrode fails to separate the three peaks and, so, shows a broad peak. However, at $\mathrm{Cu} / \mathrm{PR} / \mathrm{GCP}$ modified electrode, (solid line), DA illustrates a reversible redox couple with anodic and cathodic peaks at 350 and $190 \mathrm{mV}$. UA shows reversible oxidation peaks at 450 $\mathrm{mV}$ and AA shows irreversible behavior. The peak currents observed at
$\mathrm{Cu} / \mathrm{PR} / \mathrm{GCP}$ electrodes are much longer than those at the bare GC electrodes. This may be due to the increased surface area and/or the catalytic activity of the $\mathrm{Cu} / \mathrm{PR} / \mathrm{GCP}$ electrode. Oxidation currents increase linearly with increasing the concentration of AA, DA and UA.

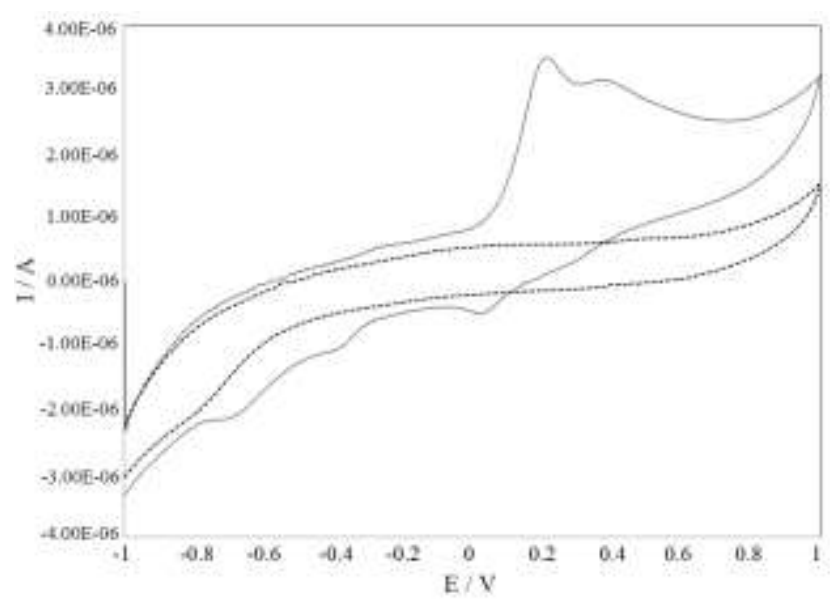

Figure 7. Cyclic voltammograms for simultaneous determination of $20 \mu \mathrm{mol} \mathrm{L}^{-1} \mathrm{DA}$, UA and AA at $\mathrm{Cu} / \mathrm{PR} / \mathrm{GCPE}$ (solid line) and bare GCE (dashed line) in $0.2 \mathrm{~mol} \mathrm{~L}^{-1}$ phosphate buffer of pH 7.0 at scan rate of $100 \mathrm{mVs}^{-1}$

The cyclic voltammetric techniques were used for the analysis of DA and UA. The cyclic voltamogram of DA and UA are shown in Figure 8. Individual calibration graphs were created as peak current vs. concentration. The curves for DA and
UA were linear over the range of 15.97$157.98 \mu \mathrm{molL}^{-1}$ and $15.97-195.35$ $\mu$ molL $\mathrm{L}^{-1}$ respectively (Figures 9 and 10). Table 1 summarizes the analytical performances of our fabricated and the literature methods in terms of linearity and limits of detection.

Table 1. Comparison of analytical performance of $\mathrm{Cu} / \mathrm{PR} / \mathrm{GCPE}$ with other modified electrodes in the

\begin{tabular}{|c|c|c|c|c|}
\hline \multicolumn{5}{|c|}{ literature } \\
\hline Electrode & Analyte & $\mathrm{LOD}_{,}^{\mathrm{a}}\left(\boldsymbol{\mu \mathrm { mol } \mathrm { L }} \mathrm{L}^{-1}\right)$ & $\mathrm{LDR}^{\mathrm{b}}{ }^{\mathrm{f}}\left(\boldsymbol{\mu m o l ~ \mathrm { L } ^ { - 1 } )}\right.$ & Ref. \\
\hline $\operatorname{Poly}(\mathrm{XO}) / \mathrm{MCPE}^{\mathrm{c}}$ & $\mathrm{DA}$ & 52.4 & - & {$[34]$} \\
\hline GN/PANI/Au/GCE ${ }^{\mathrm{d}}$ & DA & 24 & $70-1050$ & {$[35]$} \\
\hline $\mathrm{Cu} / \mathrm{PR} / \mathrm{GCPE}$ & $\mathrm{DA}$ & 4.8 & $15.97-157.98$ & This work \\
\hline $\mathrm{Cu} / \mathrm{PR} / \mathrm{GCPE}$ & UA & 3 & $15.97-195-35$ & This work \\
\hline
\end{tabular}




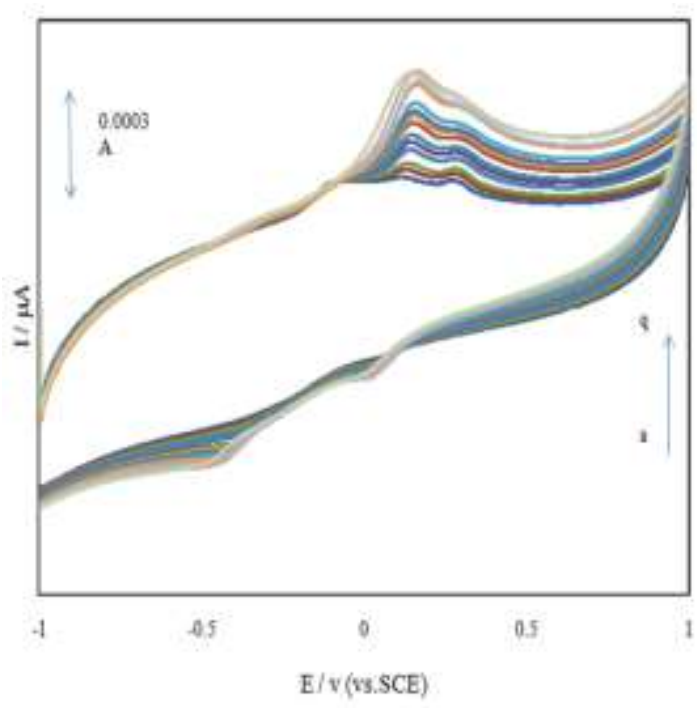

Figure 8. Cyclic voltammograms of DA and UA concentration (from a to q) $(4,8,12,16,20,30,40$, $\left.50,60,80,100,120,160,200,300,400,600 \mu \mathrm{mol} \mathrm{L}^{-1}\right)$ in the presence of AA at modified $\mathrm{Cu} / \mathrm{PR} / \mathrm{GCP}$ electrode in $\mathrm{pH} 7.0 \mathrm{PBS}$ at scan rate of $100 \mathrm{mVs}^{-1}$

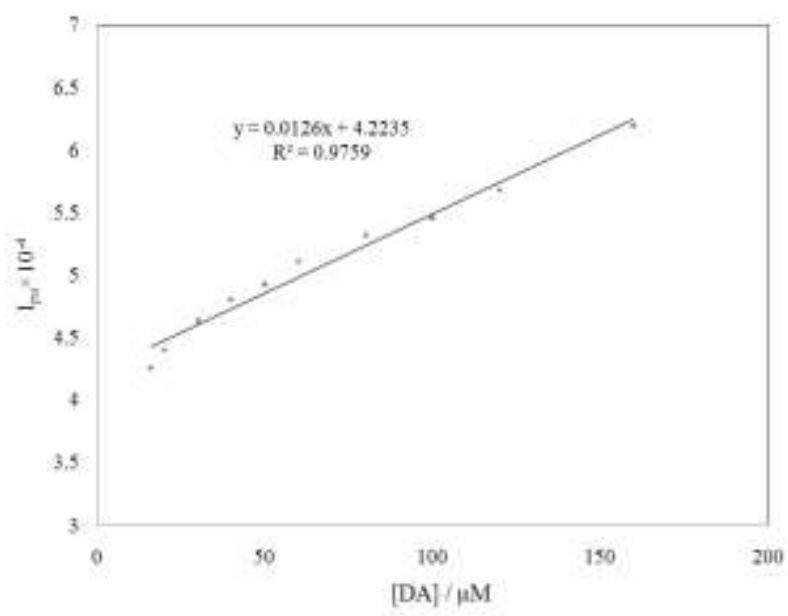

Figure 9. Anodic peak currents vs. DA concentration $\left(\mu \mathrm{mol} \mathrm{L}^{-1}\right)$ at optimum condition

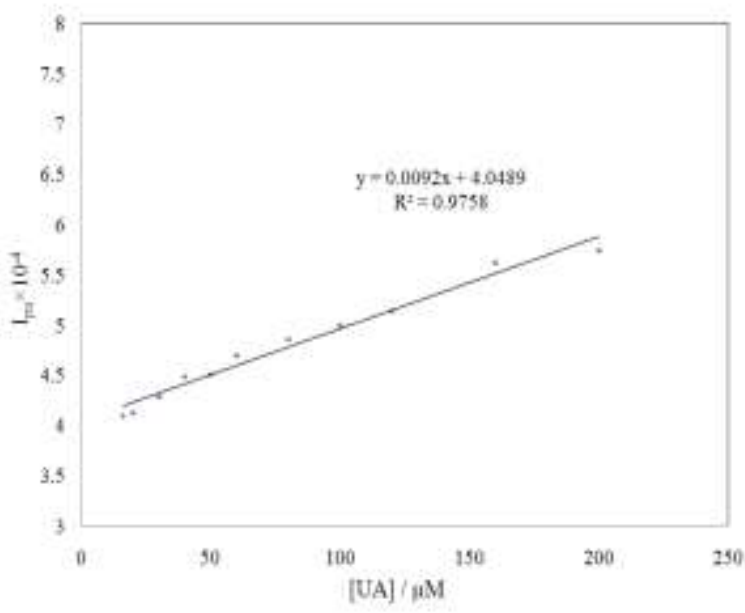

Figure 10. Anodic peak currents vs. UA concentration $\left(\mu \mathrm{mol} \mathrm{L}^{-1}\right)$ at optimum condition 


\section{Repeatability}

To characterize the repeatability of the $\mathrm{Cu} / \mathrm{PR} / \mathrm{GCP}$ modified electrode, several measurements of regeneration cycles were carried out.UA with different concentrations $(16.0,49.75,57.09 \mu \mathrm{mol}$
$\mathrm{L}^{-1}$ ) and DA with concentrations (59.9 99.0, $\quad 157.48 \quad \mu \mathrm{mol} \quad \mathrm{L}^{-1}$ ) were determined at the identical surface of $\mathrm{Cu} / \mathrm{PR} / \mathrm{GCP}$ electrode for 3 times, successively. The results were shown in Tables 2 and 3.

Table 2. Result of DA and UA determination in spiked samples

\begin{tabular}{|c|c|c|c|c|}
\hline Analyte & $\begin{array}{l}\text { UA added, } \\
\left(\mu \mathrm{mol} \mathrm{L}^{-1}\right)\end{array}$ & $\begin{array}{l}\text { UA found, } \\
\left(\mu \mathrm{mol} \mathrm{L}^{-1}\right)\end{array}$ & $\begin{array}{c}\text { RSD, \% } \\
(\mathrm{n}=3)\end{array}$ & RE, \% \\
\hline \multirow{3}{*}{ UA } & 16 & 14.1 & 0.90 & -11.87 \\
\hline & 49.75 & 44.92 & 0.173 & -9.7 \\
\hline & 57.09 & 59.6 & 0.170 & -4.2 \\
\hline \multirow{3}{*}{ DA } & 59.6 & 62.42 & 0.533 & 4.73 \\
\hline & 99 & 100.41 & 0.173 & 1.52 \\
\hline & 157.48 & 158.73 & 0.170 & 0.79 \\
\hline
\end{tabular}

RSD=Relative standard deviation $\mathrm{RE} \%=$ Relative error

Table 3. Determination of DA and UA at real samples using $\mathrm{Cu} / \mathrm{PR} / \mathrm{GCPE}$ as working electrode

\begin{tabular}{|c|c|c|c|c|}
\hline Sample & $\begin{array}{c}\text { Target } \\
\text { compound }\end{array}$ & $\begin{array}{c}\text { Added, } \\
\left.(\mu \mathrm{mol} \mathrm{L})^{-1}\right)\end{array}$ & $\begin{array}{c}\text { Found, } \\
\left.(\mu \mathrm{mol} \mathrm{L})^{-1}\right)\end{array}$ & $\begin{array}{c}\text { Recovery, } \\
\% \\
\end{array}$ \\
\hline \multirow{3}{*}{ Human serum } & \multirow{3}{*}{ DA } & 0.00 & 17.78 & - \\
\hline & & 19.6 & 36.11 & 93.67 \\
\hline & & 39.1 & 59.39 & 106.52 \\
\hline \multirow{3}{*}{ Urine } & \multirow{3}{*}{ UA } & 0.00 & 4.61 & - \\
\hline & & 19.6 & 17.61 & 66.33 \\
\hline & & 39.1 & 39.83 & 90.08 \\
\hline
\end{tabular}

All samples were analyzed using standard addition method $(n=4)$.

\section{Interferences}

The influence of various substances as potentially interfering compounds on the determination of DA and UA were investigated. The tolerance limit was defined as the maximum concentration of foreign substances, with a relative error of less than 5\%. Interference studies were conducted by exposing the $\mathrm{Cu} / \mathrm{PR} / \mathrm{GCPE}$ in a solution containing $40.0 \mu \mathrm{mol} \mathrm{L}{ }^{-1} \mathrm{DA}$ and UA in addition to the interfering substance at a $\mathrm{pH}$ level of 7.0. The results indicate that no interference was observed for common substance and ions such as $\mathrm{K}^{+}, \mathrm{Cu}^{2+}$ and $\mathrm{Cl}^{-}$but glucose in the high concentration may interfere with real sample.

\section{Conclusion}

In summary, a simple method for selective determination of DA and UA in the presence of AA has been established using cyclic voltammetry. The modified glassy carbon paste electrodes with complex of Para Red and $\mathrm{Cu}$ (II) have been successfully applied to the determination of uric acid and dopamine. The carbon paste methodology permits convenient mixing of different ligands. As the ligand is homogeneously mixed in the bulk of the paste, renewal of the surface is done simply by pressing out the paste 
from syringe, which is easier and faster. The modified electrode not only improved the catalytic oxidation of dopamine (DA) and uric acid (UA), but also resolved the anodic peaks DA and UA into two well-defined peaks at potentials 200 and $350 \mathrm{mV}$, respectively.

\section{Acknowledgments}

We are thankful to the Islamic Azad University Lamerd Branch and Payame Noor University for their support and encouragements.

\section{References}

[1] E. Andreadou, C. Nikolaou, F. Gournaras, M. Rentzos, F. Boufidou, A.Tsoutsou, C. Zournas, V. Zissimopoulos, D.V. Assilopoulos, Clin. Neurol. Neurosurg., 2009, 111, 724-728.

[2] J. Huang, Y. Liu, H. Hou, T. You, Biosens. Bioelectron., 2008, 24, 632638.

[3] L. Zhang, C. Zhang, J. Lian, Biosens. Bioelectron., 2008, 24, 690695.

[4] H. Liu, Y. Tian, Electroanal, 2008, 20, 1227-1233.

[5] R.B. Rucker, J.W. Suttie, D.B. McCormick, Handbook of vitamins, CRC Press, 2001.

[6] R.M. Wightman, L.J. May, A.C. Michael, Anal. Chem., 1988, 60, 769A793A.

[7] A. Liu, I. Honma, H. Zhou, Biosens. Bioelectron, 2005, 21, 809-816.

[8] A. Ghanemi, Alexand. J. Med., 2013, 49, 287-291.

[9] H. Kaur, B. Halliwell, Chem-Biol. Interact., 1990, 73, 235-247.

[10] J.M. Zen, Analyst, 1998, 123, 1345-1350.

[11] E. Miland, A.M. Ordieres, P.T. Blanco, M. Smyth, C. Fagain, Talan., 1996, 43,785-796.
[12] R.M. Wightman, L.J. May, A.C. Michael, Anal. Chem., 1988, 60, 769A779A.

[13] F. Gonon, M. Buda, R. Cespuglio, M. Jouvet, J.F. Pujol, Nature, 1980, 286, 902-904E.

[14] R.D. O’Neill, Analyst, 1994, 119, 767-780.

[15] (a) A. Salimi, H. Mam-Khezri, R. Hallaj, Talan, 2006, 70, 823-832; (b) S. Sajjadifar, G. Mansouri, S. Miraninezhad, Asian Journal of Nanosciences and Materials, 2018, 1, 11-18.

[16] L. Lin, P. Qiu, L. Yang, X. Cao, L. Jin, Anal. Bioanal. Chem., 2006, 384, 1308-1313.

[17] V.E. Dutt, H. Mottola, Anal. Chem., 1974, 46, 1777-1781.

[18] O. Arrigoni, M.C. De Tullio, Biochim. Biophys. Acta, 2002, 1569, 19.

[19] J. Manjunatha, B.K. Swamy, M. Deraman, G. Mamatha, Int. J. Pharm Pharm Sci., 2013, 5, 355-362.

[20] U. Chandra, B.K. Swamy, K.R. Mahanthesha, C. Vishwanath, B. Sherigara, Chem. Sens., 2013, 3, 1-6.

[21] K.R. Mahanthesha, B.K. Swamy, U. Chandra, T.V. Sathisha, S. Sarojini, K.V.K. Pai, Anal. Bioanal. Electrochem, 2013, 5, 130-138.

[22] (a) X. Lin, Q. Zhuang, J. Chen, S. Zhang, Y. Zheng, Sens. Actuat. B: Chem., 2007, 125, 240-245; (b) Z. Hosseinzadeh, A. Ramazani, N. Razzaghi-Asl, J. Chem. Rev., 2019, 1, 78-99

[23] L. Zhang, X. Lin, Anal. Bioanal. Chem., 2005, 382, 1669-1677.

[24] M.M. Sena, J.C.B. Fernandes, L. Rover R.J. Poppi, L.T. Kubota, Anal. Chim. Acta, 2000, 409, 159-170.

[25] K.H. Xue, F.F. Tao, W. Xu, S.Y. Yin, J. M. Liu, J. Electroanal. Chem., 2005, 578, 323-329. 
[26] U. Chandra, B.K. Swamy, O. [31] R. Zhang, G.D. Jin, D. Chen, X.Y. Gilbert, B. Sherigara, Electrochim. Hu, Sens. Actuate. B: Chemical, 2009, Acta, 2010, 55, 7166-7174. 138,174-181.

[27] E. Honarmand, M.H. [32] H. Sun, N. Hu, H. Ma, Motaghedifard, M. Ghamari, RSC Electroanal., 2000, 12, 1064-1070.

Advance, 2014, 4, 35511-35521.

[33] E. Laviron. J. Electroanal. Chem, 1974, 52, 395-402.

[28] A.P.D. Reis, C.R. Tarley, L.T. [34] P.V. Narayana, T. Madhusudana Reddy, P. Gopal, K. Reddaiah, P. Raghu, Res. J. Chem. Sci., 2014, 4, 371567-1573.

[29] B.J. Venton, R.M. Wightman, $J$. Neuro Chemical., 2003, 87, 1284-1295. 43.

[30] K.H. Xue, F.F. Tao, S.Y. Yin,W. [35] L. Shi, Z. Wang, G. Gou, X. Chen, Shen, W. Xu, Chem. Phys. Lett., 2004, G. Yang, W. Liu, Int. J. Electrochem. 391, 243-247. Sci., 2017, 12, 2540-2551.

How to cite this manuscript: Homa Shafiekhani, Fatemeh Mostaghni, Naimeh Rad. "Simultaneous determination of dopamine and uric acid using a glassy carbon paste electrode modified with copper- Para Red complex". Eurasian Chemical Communications, 2019, 459-469. 